\title{
Cord Blood Transplant Recipient
}

National Cancer Institute

\section{Source}

National Cancer Institute. Cord Blood Transplant Recipient. NCI Thesaurus. Code C154223.

An individual receiving a cord blood transplant. 